\title{
A Novel UC Exclusion Diet and Antibiotics for Treatment of Mild to Moderate Pediatric Ulcerative Colitis: A Prospective Open-Label Pilot Study
}

\author{
Chen Sarbagili-Shabat ${ }^{1,2}$, Lindsey Albenberg ${ }^{3}$, Johan Van Limbergen ${ }^{4,5}{ }^{(0}$, Naomi Pressman ${ }^{3}$, Anthony Otley ${ }^{6}$, \\ Michal Yaakov ${ }^{1}$, Eytan Wine ${ }^{7}\left(\mathbb{0}\right.$, Dror Weiner ${ }^{1}$ and Arie Levine ${ }^{1,2, *}$
}

1 PIBD Research Center, Paediatric Gastroenterology and Nutrition Unit, The E. Wolfson Medical Center, Holon 5822012, Israel; ibd.chen@gmail.com (C.S.-S.); michal.yaakov@walla.co.il (M.Y.); drorweiner@gmail.com (D.W.)

2 The Sackler Faculty of Medicine, Tel-Aviv University, Tel-Aviv 6997801, Israel

3 Division of Gastroenterology, Hepatology, and Nutrition, Children's Hospital of Philadelphia, Philadelphia, PA 19104, USA; AlbenbergL@chop.edu (L.A.); PressmanN@chop.edu (N.P.)

4 Division of Pediatric Gastroenterology and Nutrition, Department of Pediatrics, Amsterdam University Medical Centers, Emma Children's Hospital, 1105 AZ Amsterdam, The Netherlands; j.e.vanlimbergen@amsterdamumc.nl

5 Tytgat Institute for Liver and Intestinal Research, Amsterdam Gastroenterology Endocrinology and Metabolism, Academic Medical Center, University of Amsterdam, 1105 BK Amsterdam, The Netherlands

Citation: Sarbagili-Shabat, C.; Albenberg, L.; Van Limbergen, J.; Pressman, N.; Otley, A.; Yaakov, M. Wine, E.; Weiner, D.; Levine, A. A Novel UC Exclusion Diet and Antibiotics for Treatment of Mild to Moderate Pediatric Ulcerative Colitis: A Prospective Open-Label Pilot Study. Nutrients 2021, 13, 3736. https:// doi.org/10.3390/nu13113736

Academic Editors: Licia Pensabene and Andrea Fabbri

Received: 13 September 2021

Accepted: 21 October 2021

Published: 23 October 202

Publisher's Note: MDPI stays neutral with regard to jurisdictional claims in published maps and institutional affiliations.

Copyright: (C) 2021 by the authors Licensee MDPI, Basel, Switzerland. This article is an open access article distributed under the terms and conditions of the Creative Commons Attribution (CC BY) license (https:// creativecommons.org/licenses/by/ $4.0 /)$
6 Division of Gastroenterology and Nutrition, IWK Health Center, Halifax, NS B3K 6R8, Canada; Anthony.otley@dal.ca

7 Departments of Pediatrics and Physiology, University of Alberta, Edmonton, AB T6G 2R3, Canada; wine@ualberta.ca

* Correspondence: arie.levine.dr@gmail.com

\begin{abstract}
Background: As the microbiome plays an important role in instigating inflammation in ulcerative colitis (UC), strategies targeting the microbiome may offer an alternative therapeutic approach. The goal of the pilot trial was to evaluate the potential efficacy and feasibility of a novel UC exclusion diet (UCED) for clinical remission, as well as the potential of sequential antibiotics for diet-refractory patients to achieve remission without steroids. Methods: This was a prospective, single-arm, multicenter, open-label pilot study in patients aged 8-19, with pediatric UC activity index (PUCAI) scores $>10$ on stable maintenance therapy. Patients failing to enter remission (PUCAI $<10)$ on the diet could receive a 14-day course of amoxycillin, metronidazole and doxycycline (AMD), and were re-assessed on day 21. The primary endpoint was intention-to-treat (ITT) remission at week 6 , with UCED as the only intervention. Results: Twenty-four UCED treatment courses were given to 23 eligible children (mean age: $15.3 \pm 2.9$ years). The median PUCAI decreased from 35 (30-40) at baseline to $12.5(5-30)$ at week $6(p=0.001)$. Clinical remission with UCED alone was achieved in $9 / 24(37.5 \%)$. The median fecal calprotectin declined from $818(630.0-1880.0) \mu \mathrm{g} / \mathrm{g}$ at baseline to $592.0(140.7-1555.0) \mu \mathrm{g} / \mathrm{g}$ at week $6(p>0.05)$. Eight patients received treatment with antibiotics after failing on the diet; $4 / 8$ (50.0\%) subsequently entered remission 3 weeks later. Conclusion: The UCED appears to be effective and feasible for the induction of remission in children with mild to moderate UC. The sequential use of UCED followed by antibiotic therapy needs to be evaluated as a microbiome-targeted, steroid-sparing strategy.
\end{abstract}

Keywords: ulcerative colitis; child; diet; antibiotics; remission; treatment

\section{Introduction}

Ulcerative colitis (UC) in children is a chronic inflammatory disorder of the colon, associated with clinical symptoms including diarrhea and rectal bleeding, and has a negative impact on quality of life [1]. Epidemiologic studies have demonstrated an overall increase in the prevalence and the incidence of UC in both developed and developing 
countries [2,3]. The sharp change in food consumption from a non-Western to a Western diet has been suggested to contribute to this trend $[3,4]$. The pathogenesis of ulcerative colitis (UC) is believed to be related to dysbiosis coupled with diminished host-barrier function and unrepressed inflammation. The dysbiosis in UC is characterized by a reduction in short-chain-fatty-acid (SCFA)-producing taxa [5,6] and, in some studies, by an increase in potential pathobionts, such as Escherichia or Ruminococcus gnavus [7], or hydrogen-sulfide-reducing bacteria [6]. The manipulation of the microbiota has become one of the most intriguing targets for intervention in inflammatory bowel diseases (IBDs). Fecal microbiota transplantation (FMT), a straightforward therapy that manipulates the microbiota, has been shown to be effective in the short term in about $30 \%$ of cases [8]. The success of FMT appears to depend upon the choice of donor and their microbiota composition [9]. Recent data suggest that diet may alter intestinal microbiota, directly affect the host epithelial and goblet cells, diminish antimicrobial peptides, and influence the immune system's responses [4,10-14]. However, while dietary interventions have proven to be highly effective in inducing remission in Crohn's disease, the role of diet in UC and the potential for dietary therapies remain elusive [15-17]. A recent guideline from the international organization for the study of inflammatory bowel disease (IOIBD), primarily based on epidemiologic and animal models, suggested that patients with UC should reduce exposure to red or processed meat; saturated, trans and dairy fat; and certain additives [18]. However, there are no prospective randomized controlled trials with dietary interventions published to date that have demonstrated that a dietary intervention can induce remission in active UC in children. Currently, the only non-biologic medication for UC, which does not suppress the immune system, is 5-aminosalicylic acid (5ASA), which is considered to be the first-line therapy in mild to moderate cases. However, medications such as steroids, immunomodulators (IMM) and biologics have been increasingly used in the treatment of pediatric UC.

The manipulation of the intestinal microbiome is an emerging new strategy for the treatment of IBD, which may reduce the need for immunosuppression. Two strategies that might alter the microbiome and could be used in conjunction are diet and antibiotics. Dietary components can modulate the composition and metabolome of the gut microbiota, as well as affect the intestinal epithelium, goblet cells and innate immune system [12]. Dietary factors present in Western diets may decrease the production of mucins or cause more permeable mucous and antimicrobial peptides, as well as reshaping the microbiota $[13,19]$. Turner et al. demonstrated that patients with severe UC have an increased relative abundance of Gammaproteobacteria [7]. The presence of pathobionts may make a disease amenable to antibiotic therapy. Antibiotic combinations have been used as a microbiota-targeted therapy, including a triple combination of amoxicillin, tetracycline and metronidazole, and have been shown to be effective in active adult UC patients [20,21].

We hypothesize that the UC disease course can be controlled either by using a novel diet, developed especially for the induction of remission in UC; by an antibiotic strategy; or by both. To test the feasibility and efficacy of the diet, we decided to examine these strategies in a pilot trial in children with mild to moderate UC.

\section{Materials and Methods}

\subsection{Study Population and Design}

This was an open-label, prospective, single-arm, multicenter pilot study involving the treatment of children with active mild to moderate UC using a novel diet with an antibiotic rescue design for dietary failures. The study population targeted patients aged $8-19$, with mild to moderate active disease, defined according to the Pediatric UC Activity Index $(10 \leq$ PUCAI $\leq 45)$, at diagnosis or despite maintenance therapy with 5ASA or thiopurines, stable for at least 6 weeks. All the recruited patients meeting the inclusion and exclusion criteria (see below) were introduced to a novel dietary intervention (Supplementary Table S1) termed the Ulcerative Colitis Exclusion Diet (UCED), for the first 6 weeks, and those in remission at week 6 received a step-down diet for another 6 weeks. Patients 
with no improvement by week 3 , who failed to achieve remission by week 6 , or who deteriorated between weeks 6 and 12 could decide to receive a 14-day course of amoxicillin ( $50 \mathrm{mg} / \mathrm{kg} /$ day; max: $500 \mathrm{mg}$ of TID), metronidazole ( $15 \mathrm{mg} / \mathrm{kg} /$ day; max: $250 \mathrm{mg}$ of TID) and doxycycline (4 mg/kg/day; max: $100 \mathrm{mg}$ of BID) (AMD). Subjects with intolerance to AMD were instructed to discontinue the metronidazole. The patients on AMD were seen again 7 days after the cessation of antibiotics (Figure 1). The patients were instructed to continue their pretreatment (5ASA or immunomodulators) without any dose change. The primary outcome was the clinical remission rate (PUCAI < 10) at week 6 for the UCED intervention. The study took place at 3 sites: the Wolfson Medical Center, Holon, Israel; the Children's Hospital of Philadelphia, PA, USA; and the IWK Health Center, Halifax, NS, Canada. All the patients signed informed consent, and all the sites obtained ethical approval (NCT 02345733).

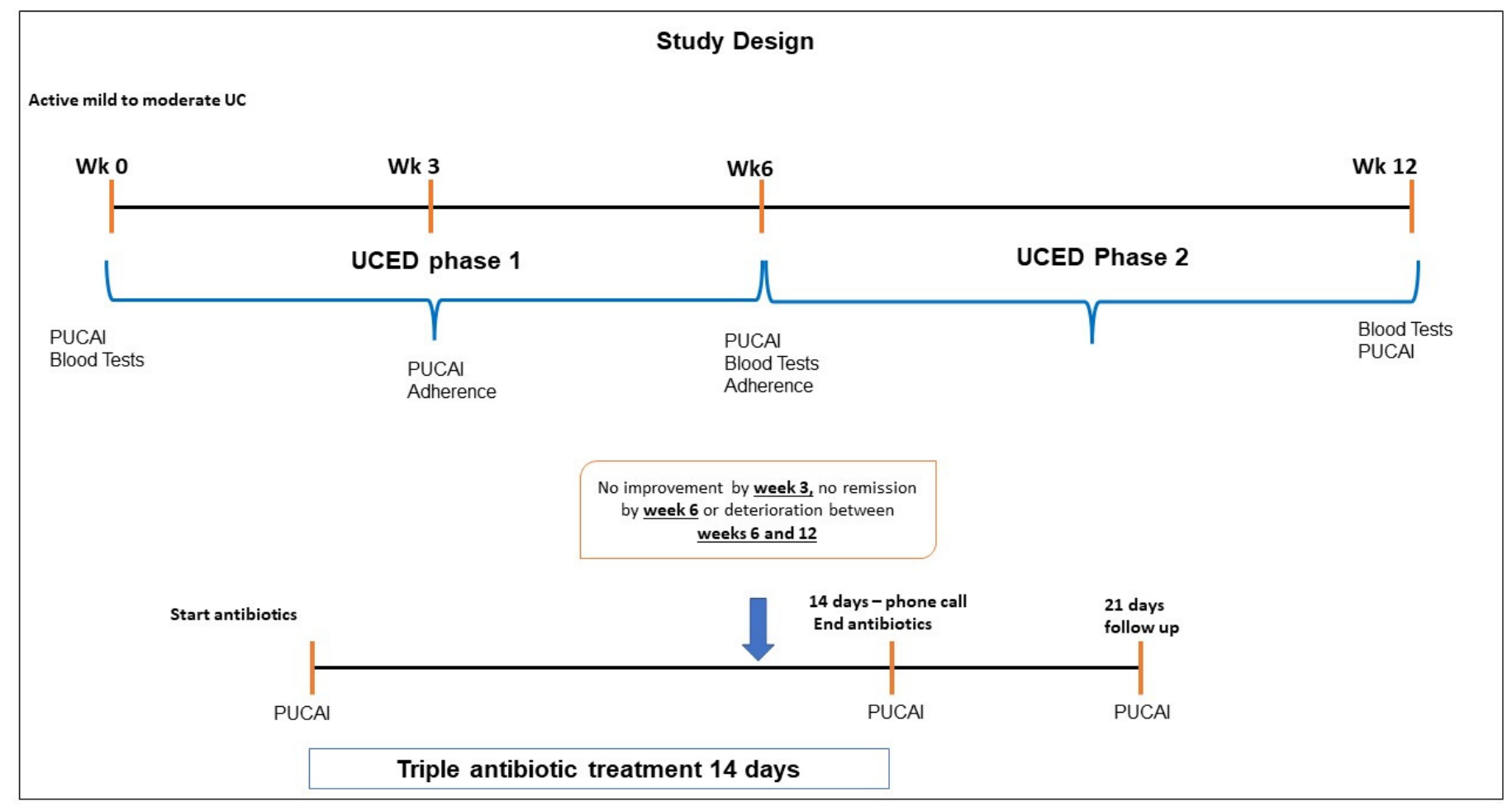

Figure 1. Trial design.

\subsection{The Ulcerative Colitis Diet Intervention}

The UCED diet was designed to alter dietary components that may adversely affect goblet cells, mucus permeability and microbiome composition, which were previously linked to UC $[10,11]$. It may be described as a low-protein, high-fiber, low-fat diet that also excludes additives. The following principles guiding food exclusion and addition included decreased exposure to sulfated amino acids (SAAs) [22-24], total protein [12,25,26], heme [27], animal fat [23,24], saturated and polyunsaturated fat [28], and food additives [29], with exposure to tryptophan [30,31] and natural sources of pectin and resistant starch $[13,27,32-34]$. The term "exclusion diet" was used, as the main principle of the diet is an exclusion of these foods' components, but some other foods were added. The diet was designed with mandatory, allowed and disallowed foods. The first-phase diet is rich in fruit and vegetables, and includes mandatory foods, primarily fruits and vegetables. There are allowed foods that can be consumed without limitation, such as rice and potatoes; foods with prescribed amounts, such as chicken, eggs, yoghurt and pasta; and disallowed foods, such as red meat and processed foods. The diet also reduces sugar and fructose intake from sources other than fruits. The second phase at weeks 7-12 is more permissive, with more options of fruits and vegetables, and additions to the prescribed amounts of 
grain products and certain pulses. The patients were instructed on the use of the diet and were provided with recipes and a dietary support system. A UCED day sample menu is presented in Supplementary Table S1.

\subsection{Inclusion and Exclusion Criteria}

The inclusion and exclusion criteria were defined based on our initial experience, showing efficacy in cases of mild-moderate UC. Our goal was to target the appropriate UC population for a pilot study that would benefit most from a novel induction dietary therapy as an induction therapy and to test its feasibility and efficacy. The inclusion criteria included informed consent; established diagnosis of UC; age between 8 and 19 years; mild to moderate active disease defined as $10 \leq$ PUCAI $\leq 45$; and stable medication (IMM/5ASA) use for the past 6 weeks or no medication. The exclusion criteria included any proven current infection, such as a positive stool culture, a parasite, or positivity for Clostridioides difficile toxin; antibiotic or steroid use in the past 2 weeks, with the exception of patients stopping steroids at enrolment; current or past use of biologics; PUCAI > 45; acute severe UC (PUCAI $\geq 65$ ) in the previous 12 months; a current extraintestinal manifestation of UC; and primary sclerosing cholangitis or liver disease, and pregnancy or an allergy to one of the antibiotics excluded patients from entering the antibiotic arm but not the diet.

\subsection{Data Collection and Dietary Assessment}

The patients were seen at baseline and weeks 3,6 and 12 . At week 2 , a phone call visit was performed to assess the PUCAI and dietary compliance. At each visit, a PUCAI score was recorded. A clinical response was defined as a decrease in PUCAI score of at least 10 points, and clinical remission was defined as PUCAI $<10$. The patients were asked to provide stool samples for fecal calprotectin (FC) at weeks 0,3 and 6, which were analyzed locally at each participating center. We performed $24 \mathrm{~h}$ recall via a dietitian at weeks 0 , 3 and 6 . The patients were asked to record the foods and beverages and the consumed amounts in a food diary (FD) over a 3-day period (weekend and 2 weekdays) at week 3. A modified diet-adherence questionnaire [16] was completed on weeks 3 and 6 . High diet adherence was determined by finding high adherence on the questionnaire and by the dietitian's assessment based on direct questioning. Poor compliance was defined by having low compliance in any assessment.

\subsection{Statistical Analysis}

Continuous variables were evaluated for distribution normality and are reported as medians (interquartile ranges, IQRs) or means (standard deviations, SDs) as appropriate. Nominal variables are summarized as frequencies and are presented as $n(\%)$. The primary end point of the proportion of patients in remission at week 6 was analyzed according to the intention-to-treat (ITT) paradigm. A pairwise comparison of the PUCAI at week 0 versus week 6/week 12 was analyzed using the Wilcoxon signed rank test and used according to the last-observation-carried-forward (LOCF) approach. A pairwise comparison of the FC at week 0 versus week 6 was analyzed using the Wilcoxon signed rank test and was performed only for subjects with parameters at both time points. The food macronutrient and micronutrient daily intake was based on the food records at baseline before starting the diet and during the UCED phase 1 at week 6 or week 3 , and was compared using the $t$-test for paired samples or the Wilcoxon signed-rank test as appropriate. Only patients with both week 0 and week $3 / 6$ diet records were entered into the nutritional analysis. All the statistical analyses were performed using the SPSS version 27 statistical analysis software (IBM, Endicott, NY, USA). All the tests were two sided and were considered to be significant at $p$ values $<0.05$. 


\section{Results}

\subsection{Study Population}

Thirty-two patients were screened between November 2014 and November 2020; eight patients were excluded (Supplementary Figure S1). Twenty-four UCED treatment courses were given to 23 eligible, consenting patients and were included in the final analysis. Significant delays in enrollment were encountered, as some of the collaborators left their institutions during the trial and there was significant delay in the ethical approval in other institutions. One patient received a second course of the UCED after a relapse two years later. The mean age of the included patients was $15.3 \pm 2.9$ years, with a mean disease duration of $1.4 \pm 1.4$ years. Demographic data are presented in Table 1. The majority had a moderate disease severity and had failed 5ASA, one patient was newly diagnosed with treatment-naïve UC, and one was coming off a course of steroids and flared.

Table 1. Characteristics of the study patients at baseline.

\begin{tabular}{|c|c|}
\hline Characteristic & Total $(n=24)$ \\
\hline Female gender, $n(\%)$ & $12(50.0)$ \\
\hline Age (years), mean (SD) & $15.3(2.9)$ \\
\hline Disease duration (years), median (IQR) & $1.0(0.4-1.9)$ \\
\hline Family history of IBD, $n(\%)$ & $5(20.8)$ \\
\hline Fecal calprotectin, $\mu \mathrm{g} / \mathrm{g},(n=18)$, median (IQR) & $818.5(630-1880)$ \\
\hline $\mathrm{CRP}, \mathrm{mg} / \mathrm{dL}$, median (IQR) & $0.5(0.3-0.5)$ \\
\hline \multicolumn{2}{|l|}{ PUCAI } \\
\hline Mean (SD) & $34.0(10.0)$ \\
\hline Median (IQR) & $35(30-40)$ \\
\hline \multicolumn{2}{|l|}{ Disease severity, PUCAI, $n(\%)$} \\
\hline Mild (10-30) & $7(29.2)$ \\
\hline Range of mild disease & $15-30$ \\
\hline Moderate (35-45) & $17(70.8)$ \\
\hline Range of moderate disease & $35-45$ \\
\hline Severe & $0(0)$ \\
\hline \multicolumn{2}{|l|}{ Disease location, $n(\%)$} \\
\hline Pancolitis & $4(16.7)$ \\
\hline Extensive & $1(4.2)$ \\
\hline Left sided & $14(58.3)$ \\
\hline Proctitis & $5(20.8)$ \\
\hline \multicolumn{2}{|l|}{ Current treatment, $n(\%)$} \\
\hline 5-ASA (oral or oral and topical) & $20(83.3)$ \\
\hline None & $3(12.5)$ \\
\hline Immunomodulators & $2(8.3)$ \\
\hline Steroids * & $1(4.2)$ \\
\hline Height (cm), mean (SD) & $161.7(13.0)$ \\
\hline Weight (kg), median (IQR) & $58.4(43.8-64.9)$ \\
\hline Weight z-score, mean (SD) & $0.04(1.3)$ \\
\hline
\end{tabular}

SD, standard deviation; IQR, interquartile range; IBD, inflammatory bowel disease; CRP, C-reactive protein PUCAI, pediatric ulcerative colitis activity index; 5-ASA, 5-aminosalicylic acid. * Steroids were stopped at inclusion.

\subsection{Response to UCED Exclusively by Week 6}

Clinical responses to UCED were achieved in 17/24 (70.8\%) patients by week 6 , and $9 / 24(37.5 \%)$ had ITT clinical remissions at week 6 with the UCED (Figure 2). One patient entered into a second remission after receiving another course of UCED, two years after the initial response. For the 23 patients, $8 / 23$ (34.8\%) had ITT clinical remissions at week 6 with the UCED. Withdrawals in remission were imputed as non-remission in the ITT analysis. The median PUCAI decreased from 35 (30-40) at baseline to 12.5 (5-30) at week 6 , and the mean PUCAI decreased from $34.0 \pm 10$ to $17.3 \pm 16.9(p=0.001)$ according to the ITT analysis including all the patients in a LOCF analysis (Figure 3). There were no differences in the baseline median PUCAI score, baseline FC levels and disease extent 
between patients who entered remission at week 6 versus treatment failures. The FC level did not vary between the recruited centers. Six patients withdrew by week 3 : two noncompliant patients (one response and one remission) and four patients who required additional therapy (Supplementary Figure S1). FC results were available for 18 patients. The median FC remained unchanged from week 0 to week $3((818(630.0-1880.0) \mu \mathrm{g} / \mathrm{g}$ and $968.0(272.0-1798.4) \mu \mathrm{g} / \mathrm{g}$, respectively $(p=0.76))$ and declined from week 3 to week 6 of the diet $((968.0(272.0-1880.0) \mu \mathrm{g} / \mathrm{g}$ to $592.0(140.7-1555.0) \mu \mathrm{g} / \mathrm{g}$, respectively $(p=0.41))$, corresponding to a $49 \%$ reduction from week 3 to week 6 ; the decline between week 0 and week 6 was not significant $(p=0.11)$. Among five patients who achieved remission at week 6 with baseline and week 6 FC, the median FC level decreased from 630 (IQR, 332-1586) $\mu \mathrm{g} / \mathrm{g}$ at week 0 to $230(75-1298) \mu \mathrm{g} / \mathrm{g}$ at week $6(p=0.14)$.

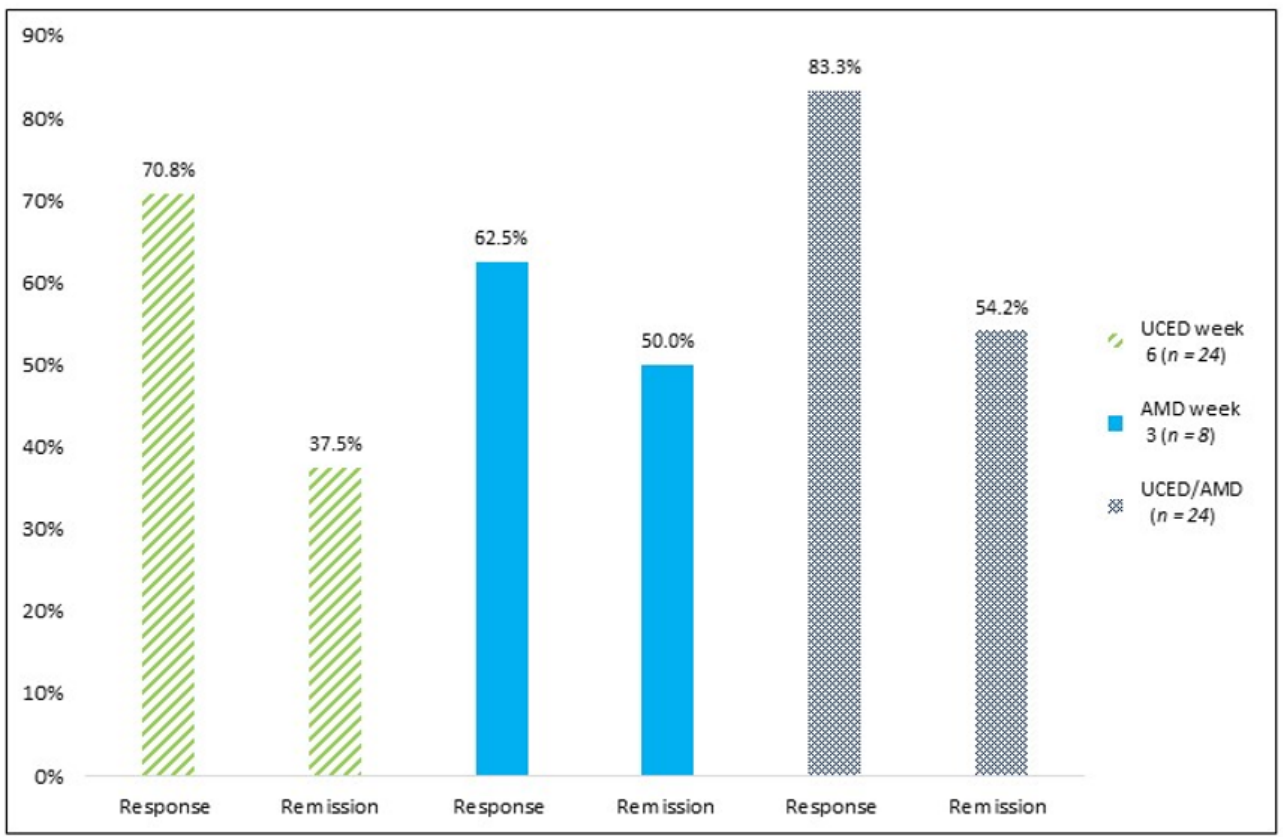

Figure 2. Response and remission rates according to intention-to-treat analysis with UC exclusion diet (UCED) as sole intervention; amoxycillin, metronidazole and doxycycline (AMD) antibiotic treatment; and either UCED or the AMD antibiotic treatment.

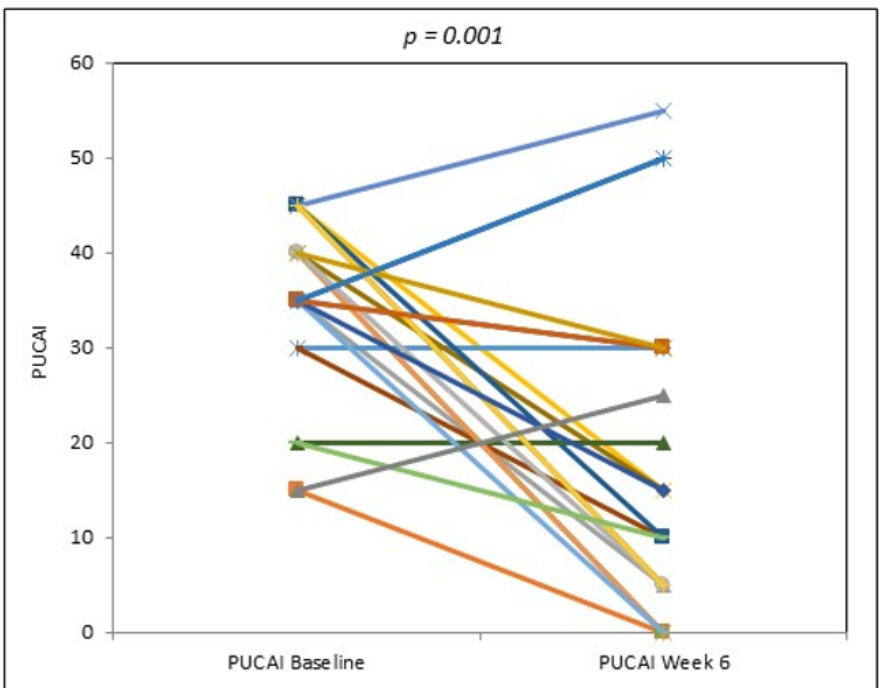

Figure 3. Change in PUCAI with UC exclusion diet between baseline and week 6, including all patients in a last-observation-carried-forward analysis. 
Among the patients who were in clinical remission at week 6, seven were slow responders and achieved clinical remission only at week 6; the other two patients achieved remission at week 2 and week 3 . Two patients achieved remission at week 2 and 3, respectively, but developed recurrence of mild symptoms by week 6 and were considered failures by ITT. One patient developed a Shigella infection during the trial that led to symptoms despite a marked reduction in FC from 1167 to 111 at week 6 . Among the patients whose PUCAIs increased from baseline to week 6, it was interesting to see that two of the three patients had proctitis with moderate disease of about 1-year duration and a family history of IBD.

\subsection{Sustained Remission with UCED at Week 12}

Six out of nine patients (66\%) maintained remission through week 12 without additional therapy; thus, clinical remission was observed in 6/24 (25\%) at week 12 based on ITT analysis. One patient withdrew despite remission and stopped the diet; two patients experienced relapses between weeks 7 and 12: one patient developed mild intermittent bleeding without other symptoms (PUCAI: 10), and one patient developed a mild relapse. The median PUCAI decreased from $35(30-40)$ at baseline to $15(5-30)$ at week $12(p=0.002)$ according to ITT analysis including all the patients in a LOCF analysis.

\subsection{Response to ADM after UCED Failure}

Eight patients received treatment with antibiotics after failing the diet; $4 / 8(50.0 \%)$ subsequently entered remission (Figure 2). Thus, in total, 13/24 (54.2\%) patients obtained remission; of those, nine patients were on the diet alone, and four, on a sequential diet and antibiotic therapy as induction therapy.

\subsection{Tolerance and Adherence}

Three patients stopped the diet (two stopped despite good responses at week 3-a PUCAI of 0 and PUCAI of 10); thus, intolerance occurred in $3 / 24$ (12.5\%). The adherence to the diet was available for $22 / 24(91.7 \%)$ patients at week $3 ; 19(86.4 \%)$ patients had high compliance, 2 had fair compliance $(9.1 \%)$ and $1(4.5 \%)$ had poor compliance. Data for adherence at week 6 were available for 15 patients among the 16 patients who reached this week; all were highly compliant.

\subsection{Nutritional Outcomes}

As the diet was designed to decrease animal saturated fat, total protein, SAAs and heme while providing fiber, we analyzed dietary intake before and after UCED. The analysis of dietary intake showed a clinically relevant decrease in total energy per day, as at baseline, the mean daily energy intake was $42.3 \pm 25.2 \mathrm{kcal} / \mathrm{kg} /$ day, versus $32.7 \pm 14.2$ at week $6(p=0.06)$. In addition to energy intake reduction, the median weight decreased from 62 (57-65) to $59 \mathrm{~kg}$ (52-63) after 6 weeks of the diet $(p=0.02)$, with a mean weight loss of $0.4 \pm 0.3 \mathrm{~kg}$ per week. Treatment with UCED was accompanied by a significant decrease in total protein, SAAs, saturated fat and iron, while there was a significant increase in total fiber consumption per day (Figure 4). 


\begin{tabular}{|cccc|}
\hline & Baseline & week 6 & \\
\hline Monounsaturated Fat (g) & $21.6 \pm 12.1$ & $27.3 \pm 12.7$ & $p=0.14$ \\
\hline Total Fiber (g) & $16.4 \pm 8.7$ & $21.7 \pm 6.5$ & $p=0.04$ \\
\hline Total Protein (g/kg) & $1.8 \pm 0.9$ & $1.2 \pm 0.6$ & $p=0.004$ \\
\hline Saturated Fat (g) & $19.5 \pm 12.5$ & $8.3 \pm 3.3$ & $p=0.001$ \\
\hline Cysteine (g) & $0.8 \pm 0.5$ & $0.5 \pm 0.4$ & $p=0.02$ \\
\hline Methionine $(\mathrm{g})$ & $1.6 \pm 1.0$ & $0.9 \pm 0.7$ & $p=0.009$ \\
\hline Iron (mg) & $12.1 \pm 8.3$ & $8.7 \pm 3.1$ & $p=0.05$ \\
\hline
\end{tabular}

Figure 4. Dietary intake of macronutrients and micronutrient targets for UCED at baseline and after diet treatment: total protein $(\mathrm{g} / \mathrm{kg}, n=20)$, saturated fat $(\mathrm{g}, n=19)$, monounsaturated fat $(\mathrm{g}, n=19)$, fiber $(\mathrm{g}, n=20)$, cysteine $(\mathrm{g}, n=15)$, methionine $(\mathrm{g}, n=15)$, and iron $(\mathrm{mg}, n=19)$.

\subsection{Safety}

During the UCED treatment, eight patients had adverse events. Three patients had worsening of disease at week 3 , two patients developed constipation, one patient lost weight during the first six weeks, and one patient developed a fever unrelated to the disease. Among the patients who received AMD, three patients had worsening of the disease, one patient had metronidazole intolerance with diarrhea, and one patient developed pneumonia one week after stopping the antibiotics.

\section{Discussion}

In this pilot study, we evaluated two therapies targeting the microbiome sequentially. The first intervention was a novel diet targeting the intestinal epithelium, goblet cells and innate immune system, in addition to the microbiota composition. The second intervention, used only in dietary-failure patients, was an established antibiotic protocol [20,21] studied in adults but never prospectively evaluated in children. The main purpose of this study was, first, to evaluate the feasibility of this specific dietary intervention, in order to improve the design and adherence, prior to starting an interventional randomized controlled trial. In light of this study's outcomes, we will test the superiority of the UCED when administered together with a 5ASA regimen, compared to 5ASA alone, in pediatric patients with mildmoderate UC in a randomized control trial.

We demonstrated clinical responses in $70 \%$ of the patients with UCED at week 6 and clinical remission in $37.5 \%$ of the patients at week 6 by ITT analysis. This was accompanied by a decline in FC, primarily after week 3 , which did not show statistical significance, likely due to the small sample size. The FC at week 6 was available for $5 / 9$ patients in remission before any change in therapy; there was a decrease in the median FC among these patients from 630 (IQR, 332-1586) $\mu \mathrm{g} / \mathrm{g}$ at week 0 to $230(75-1298) \mu \mathrm{g} / \mathrm{g}$ at week $6(p=0.14)$.

Furthermore, $50 \%$ of those who failed to obtain remission with the diet entered remission after adding a 14-day course of AMD. Thus, over $50 \%$ of the patients obtained remission without immune suppression; of those, nine patients did so on diet alone and four, on a sequential diet and antibiotic therapy as induction therapy. We chose this sequential design in order to gain insight into the independent effect of each treatment and to provide pilot data in order to proceed to randomized controlled trials in the future based on the outcomes.

The UCED diet was designed to minimize the impact of dietary components that may adversely affect goblet cells, mucus permeability and microbiome composition, which were previously linked to UC. The UCED was designed to decrease protein, SAAs and saturated fatty acids while providing fiber as a substrate for SCFA and to prevent fiber deprivation, 
which may deplete the mucus layer. We were able to demonstrate that the intake of these components was, in fact, reduced among our patients, while the fiber intake significantly increased (Figure 4). Van der Post et al. have established that a permeable mucus layer may be an early event in UC $[10,11]$. Microbial SCFA production is essential for providing fuel for epithelial cells and affects the regulation of the immune system by inducing the regulation of T-regulatory cells [35]. A high-fat diet and maltodextrin have been shown to negatively affect goblet cells [24,36-38]. Epithelial damage is also a hallmark of UC, and a high-fat diet and high-protein diet may negatively affect epithelial cells [37,39]. Permeable mucus has been associated with Proteobacteria expansion [40], and a high-fat diet has been shown to be associated with Proteobacteria and Enterobacteriaceae expansion [39,40].

Another factor that may affect the mucus layer is fiber deprivation [34]; certain fibers such as pectins might induce more viscous mucus and have an anti-inflammatory effect $[13,41]$. Finally, high levels of hydrogen sulfide may have a toxic effect on epithelial cells and can cause a breakdown of the mucin network [22]. Substrates for hydrogen-sulfide production are predominantly derived from SAAs [42], while fruits and vegetables are sources of short-chain fatty acids, which regulate the production of protein metabolites and maintain tight junctions $[43,44]$. We used these principles to design this diet, and the results of this pilot study have led us to launch a randomized control trial (NIH NCT03980405). At this juncture, we cannot be certain which components that were included or excluded were responsible for the clinical effect or what the effect upon the microbiome was.

There are a few clinical studies that have suggested a link between diet and UC, but the data are conflicting. A prospective interventional crossover study in $18 \mathrm{UC}$ adult patients showed that a low-fat, high-fiber diet decreased markers of inflammation and reduced intestinal dysbiosis [45]. A large prospective UC cohort followed from remission suggested that relapse was associated with the intake of the saturated fatty acid myristic acid, found primarily in grain-fed beef and dairy $[28,46]$. The benefit of plant-based diets (PBD) in UC patients was demonstrated by Chiba M. et al. to contribute to preventing relapse at one-year follow-up in UC patients; therapy incorporating a PBD was shown to induce remission in about one-third of patients with mild UC [47]. However, a large Swiss prospective cohort study showed that vegetarians had no advantage over omnivores with regard to disease activity, hospitalizations, complications or surgery with UC [48].

Most of the patients in our study tolerated the diet well, and only $12 \%$ discontinued the diet. Interestingly, two of these patients were in remission at week 3 and had a mild increase in symptoms by week six; one patient who had responded very well to the diet developed a Shigella infection during the trial that led to symptoms, despite a marked reduction in FC from 1167 to 111 at week 6; these four patients were considered failures in the ITT analysis.

We observed that the majority of the patients responded to the diet only between weeks 3 and 6; this is supported by the FC data, which did not show a decline between baseline and week 3 but showed a $49 \%$ decline between weeks 3 and 6 . This differs from the response to exclusive enteral nutrition or the Crohn's disease exclusion diet, in which the response was rapid and the majority of patients achieved remission during the first 3 weeks of dietary therapy [49]. Despite the decline, the median FC remained high at week 6; larger studies are required to detect the impact of diet on gut healing, including performing colonoscopies.

Antibiotics may be a double-edged sword in IBD. Antibiotics may increase dysbiosis and increase the translocation of bacteria [50] but, on the other hand, may be effective in refractory patients $[7,20,21]$, and there is an interaction between diet and antibiotics with regard to inflammation in rodent models (a high-fat diet may increase antibiotic-induced dysbiosis) [39]. To date, the utility of the antibiotic combination we used in the trial has been demonstrated prospectively only for severe or steroid-dependent adult UC [7,20,21]. Here, we demonstrate, in a small cohort of diet-refractory patients, that antibiotic therapy may have benefit in achieving remission, and a prospective randomized controlled trial is currently underway to evaluate this further. 
There are several limitations of this study. This was a pilot trial used to generate data and conducted as a proof of concept, to allow progress to larger trials if the data were positive. Thus, the sample size was limited. We only investigated children with mild to moderate disease; based on previous clinical experience, this group is the most likely to benefit from the combination of diet and antibiotics, and this combination might be used to avoid steroids and immunosuppressive therapy in the future. We were also hampered by the fact that not all the patients provided FC samples as requested. In addition, we saw a weight reduction after 6 weeks of the diet, which might indicate that the diet is not suitable for severe cases of UC with malnutrition. Another weakness of the study is that we did not perform colonoscopy in order to evaluate mucosal healing. However, recently, we have published a randomized controlled trial in adult patients with active refractory UC, showing that the UCED alone appeared to achieve mucosal healing versus single-donor fecal transplantation with or without diet, as mucosal healing (Mayo 0) was achieved only in the group that received the $\operatorname{UCED}(3 / 15,20 \%)$ vs. $0 / 36$ of the patients who received fecal transplantation $(p=0.022)$ [51]. However, we emphasize that, without a placebo group, caution needs to be taken in interpreting our results, as some of the response could be mediated by placebo effects. The strengths of this pilot trial were the prospective nature and use of defined criteria for inclusion and remission, as well as it being the first report of this novel diet.

In conclusion, the results of this pilot trial suggest that both diet and antibiotics may have a role for the induction of remission in mild to moderate UC in children. This needs to be explored further with a larger sample size. Randomized controlled trials are now underway with both therapies to provide more evidence for these therapies, which could facilitate the use of microbiome-targeted therapies in conjunction with other medical therapy or instead of immune suppression in the future.

Supplementary Materials: The following are available online at https:/ / www.mdpi.com/article/10 $.3390 /$ nu13113736/s1. Figure S1: Participant flow diagram, Table S1: A day's sample menu for phase 1 UCED.

Author Contributions: C.S.-S. and A.L. conceived and planned the study, recruited patients, interpreted the data and drafted the manuscript. L.A., J.V.L., N.P., A.O., M.Y., E.W. and D.W. recruited patients and performed critical revision of the manuscript. All authors have read and agreed to the published version of the manuscript.

Funding: This study was supported by donation from the Solomon Foundation, the PIBD center dietary research program is funded by a grant from the Azrieli Foundation.

Institutional Review Board Statement: The study was conducted according to the guidelines of the Declaration of Helsinki, and approved by the local institutional ethical committee of the Wolfson Medical Center, Holon, Israel (protocol approval code 0096-14-WOMC, 070-015-WOMC); the Children's Hospital of Philadelphia, PA, USA (protocol approval code 16-013075); and the IWK Health Center, Halifax, NS, Canada (protocol approval code 1019695).

Informed Consent Statement: Informed consent was obtained from all subjects involved in the study.

Data Availability Statement: The data underlying this article are available in the article and in its online supplementary material.

Conflicts of Interest: C.S.-S.: potential IP for Nestle Health Science. LA. has received grants, honoraria, and speaker or consulting fees from Abbott Nutrition, Nestle Health Science, and Seres Therapeutics. J.V.L.: consulting, travel and/or speaker fees and research support from AbbVie, Janssen, Nestlé Health Science, Merck, P\&G, GSK, Illumina and Otsuka. The conduct of the study in Halifax, Canada, was supported by local divisional funds, a Canadian Institutes of Health Research (CIHR: Canadian Association of Gastroenterology-Crohn's Colitis Canada) New Investigator award (J.V.L.) and a Canada Research Chair Tier 2 in Translational Microbomics (J.V.L.). A.O. has received grants and consulting fees, and/or sits on advisory boards for Janssen, AbbVie, Pfizer, Eli Lily and Nestle Health Science. M.Y. has no conflicts of interest. E.W. has received honoraria from Janssen \& 
Mead Johnson Nutrition (speaker fee) and from AbbVie and Nestle Health Sciences (advisory board and speaker fees). D.W. has no conflicts of interest. A.L. has received grants, honoraria, speaker or consulting fees, or IP licensing from Janssen, Megapharm, Takeda, Ferring, Galapagos and Nestle Health Science.

$\begin{array}{ll}\text { Abbreviations } \\ \text { UC } & \text { Ulcerative Colitis } \\ \text { UCED } & \text { Ulcerative Colitis Exclusion Diet } \\ \text { PUCAI } & \text { Pediatric UC Activity Index } \\ \text { ITT } & \text { Intention to Treat } \\ \text { IBD } & \text { Inflammatory Bowel Disease } \\ \text { 5ASA } & \text { 5-Aminosalicylic Acid } \\ \text { IMM } & \text { Immune Modulator } \\ \text { FC } & \text { Fecal Calprotectin } \\ \text { LOCF } & \text { Last Observation Carried Forward } \\ \text { IQR } & \text { Interquartile Range } \\ \text { AMD } & \text { Amoxycillin, Metronidazole and Doxycycline } \\ \text { SAAs } & \text { Sulfated Amino Acids }\end{array}$

\section{References}

1. Lönnfors, S.; Vermeire, S.; Greco, M.; Hommes, D.; Bell, C.; Avedano, L. IBD and health-related quality of life-Discovering the true impact. J. Crohn's Coliti 2014, 8, 1281-1286. [CrossRef]

2. Molodecky, N.A.; Soon, I.S.; Rabi, D.M.; Ghali, W.A.; Ferris, M.; Chernoff, G.; Benchimol, E.I.; Panaccione, R.; Ghosh, S.; Barkema, H.W.; et al. Increasing Incidence and Prevalence of the Inflammatory Bowel Diseases with Time, Based on Systematic Review. Gastroenterology 2012, 142, 46-54.e42. [CrossRef] [PubMed]

3. Kaplan, G.G.; Ng, S.C. Understanding and Preventing the Global Increase of Inflammatory Bowel Disease. Gastroenterology 2017, 152, 313-321.e2. [CrossRef]

4. Levine, A.; Boneh, R.S.; Wine, E. Evolving role of diet in the pathogenesis and treatment of inflammatory bowel diseases. Gut 2018, 67, 1726-1738. [CrossRef] [PubMed]

5. James, S.L.; Christophersen, C.T.; Bird, A.R.; Conlon, M.A.; Rosella, O.; Gibson, P.R.; Muir, J.G. Abnormal fibre usage in UC in remission. Gut 2014, 64, 562-570. [CrossRef] [PubMed]

6. Khalil, N.A.; Walton, G.E.; Gibson, G.R.; Tuohy, K.M.; Andrews, S.C. In vitrobatch cultures of gut microbiota from healthy and ulcerative colitis (UC) subjects suggest that sulphate-reducing bacteria levels are raised in UC and by a protein-rich diet. Int. J. Food Sci. Nutr. 2013, 65, 79-88. [CrossRef]

7. Turner, D.; Bishai, J.; Reshef, L.; Abitbol, G.; Focht, G.; Marcus, D.; Ledder, O.; Lev-Tzion, R.; Orlanski-Meyer, E.; Yerushalmi, B.; et al. Antibiotic Cocktail for Pediatric Acute Severe Colitis and the Microbiome: The PRASCO Randomized Controlled Trial. Inflamm. Bowel Dis. 2019, 26, 1733-1742. [CrossRef] [PubMed]

8. Costello, S.P.; Soo, W.; Bryant, R.V.; Jairath, V.; Hart, A.L.; Andrews, J.M. Systematic review with meta-analysis: Faecal microbiota transplantation for the induction of remission for active ulcerative colitis. Aliment. Pharmacol. Ther. 2017, 46, 213-224. [CrossRef]

9. Moayyedi, P.; Surette, M.G.; Kim, P.T.; Libertucci, J.; Wolfe, M.; Onischi, C.; Armstrong, D.; Marshall, J.K.; Kassam, Z.; Reinisch, W.; et al. Fecal Microbiota Transplantation Induces Remission in Patients with Active Ulcerative Colitis in a Randomized Controlled Trial. Gastroenterology 2015, 149, 102-109.e6. [CrossRef] [PubMed]

10. Johansson, M.E.V.; Gustafsson, J.K.; Holmén-Larsson, J.; Jabbar, K.; Xia, L.; Xu, H.; Ghishan, F.K.; A Carvalho, F.; Gewirtz, A.T.; Sjövall, H.; et al. Bacteria penetrate the normally impenetrable inner colon mucus layer in both murine colitis models and patients with ulcerative colitis. Gut 2013, 63, 281-291. [CrossRef] [PubMed]

11. van der Post, S.; Jabbar, K.; Birchenough, G.; Arike, L.; Akhtar, N.; Sjovall, H.; Johansson, M.E.V.; Hansson, G.C. Structural weakening of the colonic mucus barrier is an early event in ulcerative colitis pathogenesis. Gut 2019, 68, 2142-2151. [CrossRef]

12. Llewellyn, S.R.; Britton, G.J.; Contijoch, E.J.; Vennaro, O.H.; Mortha, A.; Colombel, J.-F.; Grinspan, A.; Clemente, J.C.; Merad, M.; Faith, J.J. Interactions Between Diet and the Intestinal Microbiota Alter Intestinal Permeability and Colitis Severity in Mice. Gastroenterology 2018, 154, 1037-1046.e2. [CrossRef]

13. Puértolas-Balint, F.; Schroeder, B.O. Does an Apple a Day Also Keep the Microbes Away? The Interplay Between Diet, Microbiota, and Host Defense Peptides at the Intestinal Mucosal Barrier. Front. Immunol. 2020, 11, 1164. [CrossRef]

14. Zaidi, D.; Huynh, H.Q.; Carroll, M.W.; Mandal, R.; Wishart, D.S.; Wine, E. Gut Microenvironment and Bacterial Invasion in Paediatric Inflammatory Bowel Diseases. J. Pediatr. Gastroenterol. Nutr. 2020, 71, 624-632. [CrossRef] [PubMed]

15. Miele, E.; Shamir, R.; Aloi, M.; Assa, A.; Braegger, C.; Bronsky, J.; de Ridder, L.; Escher, J.C.; Hojsak, I.; Kolaček, S.; et al. Nutrition in Pediatric Inflammatory Bowel Disease: A Position Paper on Behalf of the Porto Inflammatory Bowel Disease Group of the European Society of Pediatric Gastroenterology, Hepatology and Nutrition. J. Pediatr. Gastroenterol. Nutr. 2018, 66, 687-708. [CrossRef] [PubMed] 
16. Levine, A.; Wine, E.; Assa, A.; Boneh, R.S.; Shaoul, R.; Kori, M.; Cohen, S.; Peleg, S.; Shamaly, H.; On, A.; et al. Crohn's Disease Exclusion Diet Plus Partial Enteral Nutrition Induces Sustained Remission in a Randomized Controlled Trial. Gastroenterology 2019, 157, 440-450.e8. [CrossRef] [PubMed]

17. Sarbagili-Shabat, C.; Sigall-Boneh, R.; Levine, A. Nutritional therapy in inflammatory bowel disease. Curr. Opin. Gastroenterol. 2015, 31, 303-308. [CrossRef]

18. Levine, A.; Rhodes, J.M.; Lindsay, J.O.; Abreu, M.T.; Kamm, M.A.; Gibson, P.R.; Gasche, C.; Silverberg, M.S.; Mahadevan, U.; Boneh, R.S.; et al. Dietary Guidance from the International Organization for the Study of Inflammatory Bowel Diseases. Clin. Gastroenterol. Hepatol. 2020, 18, 1381-1392. [CrossRef]

19. Chen, L.; Wang, J.; Yi, J.; Liu, Y.; Yu, Z.; Chen, S.; Liu, X. Increased mucin-degrading bacteria by high protein diet leads to thinner mucus layer and aggravates experimental colitis. J. Gastroenterol. Hepatol. 2021, 36, 2864-2874. [CrossRef] [PubMed]

20. Uehara, T.; Kato, K.; Ohkusa, T.; Sugitani, M.; Ishii, Y.; Nemoto, N.; Moriyama, M. Efficacy of antibiotic combination therapy in patients with active ulcerative colitis, including refractory or steroid-dependent cases. J. Gastroenterol. Hepatol. 2010, 25, S62-S66. [CrossRef] [PubMed]

21. Ohkusa, T.; Kato, K.; Terao, S.; Chiba, T.; Mabe, K.; Murakami, K.; Mizokami, Y.; Sugiyama, T.; Yanaka, A.; Takeuchi, Y.; et al. Newly Developed Antibiotic Combination Therapy for Ulcerative Colitis: A Double-Blind Placebo-Controlled Multicenter Trial. Am. J. Gastroenterol. 2010, 105, 1820-1829. [CrossRef] [PubMed]

22. Kushkevych, I.; Cejnar, J.; Treml, J.; Dordević, D.; Kollar, P.; Vítězová, M. Recent Advances in Metabolic Pathways of Sulfate Reduction in Intestinal Bacteria. Cells 2020, 9, 698. [CrossRef]

23. Devkota, S.; Wang, Y.; Musch, M.W.; Leone, V.; Fehlner-Peach, H.; Nadimpalli, A.; Antonopoulos, D.A.; Jabri, B.; Chang, E.B. Dietary-fat-induced taurocholic acid promotes pathobiont expansion and colitis in Il10 ${ }^{-}{ }^{-}$mice. Nature 2012, 487, $104-108$. [CrossRef] [PubMed]

24. Tomas, J.; Mulet, C.; Saffarian, A.; Cavin, J.-B.; Ducroc, R.; Regnault, B.; Tan, C.K.; Duszka, K.; Burcelin, R.; Wahli, W.; et al. High-fat diet modifies the PPAR- $\gamma$ pathway leading to disruption of microbial and physiological ecosystem in murine small intestine. Proc. Natl. Acad. Sci. USA 2016, 113, E5934-E5943. [CrossRef]

25. Vidal-Lletjós, S.; Beaumont, M.; Tomé, D.; Benamouzig, R.; Blachier, F.; Lan, A. Dietary Protein and Amino Acid Supplementation in Inflammatory Bowel Disease Course: What Impact on the Colonic Mucosa? Nutrients 2017, 9, 310. [CrossRef] [PubMed]

26. Mu, C.; Yang, Y.; Luo, Z.; Guan, L.; Zhu, W. The Colonic Microbiome and Epithelial Transcriptome Are Altered in Rats Fed a High-Protein Diet Compared with a Normal-Protein Diet. J. Nutr. 2016, 146, 474-483. [CrossRef] [PubMed]

27. Le Leu, R.K.; Young, G.P.; Hu, Y.; Winter, J.; Conlon, M.A. Dietary Red Meat Aggravates Dextran Sulfate Sodium-Induced Colitis in Mice Whereas Resistant Starch Attenuates Inflammation. Dig. Dis. Sci. 2013, 58, 3475-3482. [CrossRef] [PubMed]

28. Barnes, E.L.; Nestor, M.; Onyewadume, L.; de Silva, P.S.; Korzenik, J.R.; Aguilar, H.; Bailen, L.; Berman, A.; Bhaskar, S.K.; Brown, M.; et al. High Dietary Intake of Specific Fatty Acids Increases Risk of Flares in Patients with Ulcerative Colitis in Remission during Treatment with Aminosalicylates. Clin. Gastroenterol. Hepatol. 2017, 15, 1390-1396.e1. [CrossRef] [PubMed]

29. Chassaing, B.; Van De Wiele, T.; De Bodt, J.; Marzorati, M.; Gewirtz, A.T. Dietary emulsifiers directly alter human microbiota composition and gene expression ex vivo potentiating intestinal inflammation. Gut 2017, 66, 1414-1427. [CrossRef]

30. Alvarado, D.M.; Chen, B.; Iticovici, M.; Thaker, A.I.; Dai, N.; VanDussen, K.L.; Shaikh, N.; Lim, E.; Guillemin, G.; Tarr, P.I.; et al. Epithelial Indoleamine 2,3-Dioxygenase 1 Modulates Aryl Hydrocarbon Receptor and Notch Signaling to Increase Differentiation of Secretory Cells and Alter Mucus-Associated Microbiota. Gastroenterology 2019, 157, 1093-1108.e11. [CrossRef] [PubMed]

31. Agus, A.; Planchais, J.; Sokol, H. Gut Microbiota Regulation of Tryptophan Metabolism in Health and Disease. Cell Host Microbe 2018, 23, 716-724. [CrossRef]

32. Wei, Y.; Gong, J.; Zhu, W.; Tian, H.; Ding, C.; Gu, L.; Li, N.; Li, J. Pectin enhances the effect of fecal microbiota transplantation in ulcerative colitis by delaying the loss of diversity of gut flora. BMC Microbiol. 2016, 16, 255. [CrossRef] [PubMed]

33. Sahasrabudhe, N.M.; Beukema, M.; Tian, L.; Troost, B.; Scholte, J.; Bruininx, E.; Bruggeman, G.; Berg, M.V.D.; Scheurink, A.; Schols, H.A.; et al. Dietary Fiber Pectin Directly Blocks Toll-Like Receptor 2-1 and Prevents Doxorubicin-Induced Ileitis. Front. Immunol. 2018, 9, 383. [CrossRef]

34. Desai, M.S.; Seekatz, A.M.; Koropatkin, N.M.; Kamada, N.; Hickey, C.A.; Wolter, M.; Pudlo, N.A.; Kitamoto, S.; Terrapon, N.; Muller, A.; et al. A Dietary Fiber-Deprived Gut Microbiota Degrades the Colonic Mucus Barrier and Enhances Pathogen Susceptibility. Cell 2016, 167, 1339-1353.e21. [CrossRef]

35. Russo, E.; Giudici, F.; Fiorindi, C.; Ficari, F.; Scaringi, S.; Amedei, A. Immunomodulating Activity and Therapeutic Effects of Short Chain Fatty Acids and Tryptophan Post-biotics in Inflammatory Bowel Disease. Front. Immunol. 2019, 10, 2754. [CrossRef] [PubMed]

36. Martinez-Medina, M.; Denizot, J.; Dreux, N.; Robin, F.; Billard, E.; Bonnet, R.; Darfeuille-Michaud, A.; Barnich, N. Western diet induces dysbiosis with increasedE coliin CEABAC10 mice, alters host barrier function favouring AIEC colonisation. Gut 2013, 63, 116-124. [CrossRef]

37. Gulhane, M.; Murray, L.; Lourie, R.; Tong, H.; Sheng, Y.H.; Wang, R.; Kang, A.; Schreiber, V.; Wong, K.Y.; Magor, G.; et al. High Fat Diets Induce Colonic Epithelial Cell Stress and Inflammation that is Reversed by IL-22. Sci. Rep. 2016, 6, 28990. [CrossRef]

38. Laudisi, F.; Di Fusco, D.; Dinallo, V.; Stolfi, C.; Di Grazia, A.; Marafini, I.; Colantoni, A.; Ortenzi, A.; Alteri, C.; Guerrieri, F.; et al. The Food Additive Maltodextrin Promotes Endoplasmic Reticulum Stress-Driven Mucus Depletion and Exacerbates Intestinal Inflammation. Cell. Mol. Gastroenterol. Hepatol. 2019, 7, 457-473. [CrossRef] [PubMed] 
39. Lee, J.-Y.; Cevallos, S.A.; Byndloss, M.X.; Tiffany, C.R.; Olsan, E.E.; Butler, B.P.; Young, B.M.; Rogers, A.W.; Nguyen, H.; Kim, K.; et al. High-Fat Diet and Antibiotics Cooperatively Impair Mitochondrial Bioenergetics to Trigger Dysbiosis that Exacerbates Pre-inflammatory Bowel Disease. Cell Host Microbe 2020, 28, 273-284.e6. [CrossRef] [PubMed]

40. E Jakobsson, H.; Rodríguez-Piñeiro, A.M.; Schütte, A.; Ermund, A.; Boysen, P.; Bemark, M.; Sommer, F.; Bäckhed, F.; Hansson, G.C.; Johansson, M.E.V. The composition of the gut microbiota shapes the colon mucus barrier. EMBO Rep. 2014, 16, 164-177. [CrossRef]

41. Singh, V.; Yeoh, B.S.; Walker, R.; Xiao, X.; Saha, P.; Golonka, R.M.; Cai, J.; Bretin, A.C.A.; Cheng, X.; Liu, Q.; et al. Microbiota fermentation-NLRP3 axis shapes the impact of dietary fibres on intestinal inflammation. Gut 2019, 68, 1801-1812. [CrossRef] [PubMed]

42. Ijssennagger, N.; van der Meer, R.; van Mil, S.W. Sulfide as a Mucus Barrier-Breaker in Inflammatory Bowel Disease? Trends Mol. Med. 2016, 22, 190-199. [CrossRef] [PubMed]

43. Sittipo, P.; Shim, J.-W.; Lee, Y.K. Microbial Metabolites Determine Host Health and the Status of Some Diseases. Int. J. Mol. Sci. 2019, 20, 5296. [CrossRef]

44. Kellingray, L.; Tapp, H.S.; Saha, S.; Doleman, J.F.; Narbad, A.; Mithen, R.F. Consumption of a diet rich in Brassica vegetables is associated with a reduced abundance of sulphate-reducing bacteria: A randomised crossover study. Mol. Nutr. Food Res. 2017, 61, 1600992. [CrossRef] [PubMed]

45. Fritsch, J.; Garces, L.; Quintero, M.A.; Pignac-Kobinger, J.; Santander, A.M.; Fernández, I.; Ban, Y.J.; Kwon, D.; Phillips, M.C.; Knight, K.; et al. Low-Fat, High-Fiber Diet Reduces Markers of Inflammation and Dysbiosis and Improves Quality of Life in Patients with Ulcerative Colitis. Clin. Gastroenterol. Hepatol. 2021, 19, 1189-1199.e30. [CrossRef]

46. A Daley, C.; Abbott, A.; Doyle, P.S.; A Nader, G.; Larson, S. A review of fatty acid profiles and antioxidant content in grass-fed and grain-fed beef. Nutr. J. 2010, 9, 10. [CrossRef] [PubMed]

47. Sugawara, T. Relapse Prevention by Plant-Based Diet Incorporated into Induction Therapy for Ulcerative Colitis: A Single-Group Trial. Perm. J. 2019, 23, 18-220. [CrossRef]

48. Schreiner, P.; Yilmaz, B.; Rossel, J.-B.; Franc, Y.; Misselwitz, B.; Scharl, M.; Zeitz, J.; Frei, P.; Greuter, T.; Vavricka, S.R.; et al. Vegetarian or gluten-free diets in patients with inflammatory bowel disease are associated with lower psychological well-being and a different gut microbiota, but no beneficial effects on the course of the disease. United Eur. Gastroenterol. J. 2019, 7, 767-781. [CrossRef] [PubMed]

49. Boneh, R.S.; Van Limbergen, J.; Wine, E.; Assa, A.; Shaoul, R.; Milman, P.; Cohen, S.; Kori, M.; Peleg, S.; On, A.; et al. Dietary Therapies Induce Rapid Response and Remission in Pediatric Patients with Active Crohn's Disease. Clin. Gastroenterol. Hepatol. 2020, 19, 752-759. [CrossRef] [PubMed]

50. Knoop, K.; Gustafsson, J.K.; McDonald, K.G.; Kulkarni, D.H.; Kassel, R.; Newberry, R.D. Antibiotics promote the sampling of luminal antigens and bacteria via colonic goblet cell associated antigen passages. Gut Microbes 2017, 8, 400-411. [CrossRef]

51. Shabat, C.S.; Scaldaferri, F.; Zittan, E.; Hirsch, A.; Mentella, M.C.; Musca, T.; Cohen, N.A.; Ron, Y.; Isakov, N.F.; Pfeffer, J.; et al. Use of Fecal transplantation with a novel diet for mild to moderate active ulcerative colitis: The CRAFT UC randomized controlled trial. J. Crohn's Coliti 2021, jjab165. [CrossRef] [PubMed] 